\title{
O ALCANCE DA SEGURIDADE SOCIAL BRASILEIRA AOS SOCIALMENTE DESPROTEGIDOS
}

\author{
THE REACHING FOR BRASILIAN SOCIAL SECURITY TO THE SOCIALLY \\ UNPROTECTED
}

Raquel Sabará Freitas e Maria Helena Cariaga

Universidade Federal do Tocantins - UFT

\begin{abstract}
RESUMO
O objetivo deste artigo é refletir se a atual conformação da seguridade social brasileira permite levar à universalização da mesma. A partir dos conceitos de "socialmente protegido e desprotegido" adotados pelo Conselho Nacional da Previdência Social (CNPS), reflete-se sobre o alcance da seguridade social aos socialmente desprotegidos. Trata-se de um estudo teórico analítico, realizado mediante a análise do arcabouço normativo da seguridade social no Brasil. Conclui-se que tais conceitos levam a um entendimento de proteção social onde há uma relação de complementaridade entre o direito à previdência social e à assistência social sem possibilidade de universalização dessa proteção. A universalização requerer, não só indissociabilidade e complementaridade entre as duas políticas - de previdência e de assistência social -, como também políticas econômicas e sociais onde o trabalho e a garantia de reprodução social dos indivíduos sejam tidos como direitos de cidadania.
\end{abstract}

Palavras-chave: Seguridade Social; Assistência Social; Socialmente Desprotegidos.

\begin{abstract}
The objective of this article is to reflect the current conformation of Brazilian Social Security which permits the universalization of the same. Based on the protected and unprotected social concepts adopted by the National Council of Social Welfare (CNP), which reflects on the scope on social security to the socially unprotected. This is an exploratory study conducted by a normative framework of social security in Brazil. It is concluded that such concepts lead to an understanding of social protection where there is a complementary relation between the right to social security and social assistance without the possibily of universalization of this protection. The universalization requires not only inseparability and complementarity between the two polices - as well as the political, economic and social polices where work and the guarantee of social reproduction of individuals be taken as citizenships rights.
\end{abstract}

Key Words: Social Security; Social Assistance; Socially Unprotected.

Recebido em 15/09/2014. Aceito em 11/12/2014. Publicado em 14/01/2015.

\section{INTRODUÇÃO}

O estudo trata do tema da seguridade social brasileira e da proteção dos socialmente desprotegidos. O objetivo deste artigo é refletir se a atual conformação da seguridade social brasileira permite levar à universalização da mesma. Para tal, primeiramente busca-se analisar 
a concepção de proteção social implícita nos conceitos de socialmente protegido e desprotegido do Conselho Nacional da Previdência Social (CNPS). Por último, a partir de tal conceito, procura-se analisar o alcance do direito à previdência social e à assistência social aos socialmente desprotegidos.

Nossa preocupação relaciona-se com o direito ao trabalho e a garantia de reprodução social dos indivíduos, como direitos de cidadania. Na ausência do trabalho como único meio de reprodução social do indivíduo, seja garantido a ele uma proteção da seguridade social. Direito não somente a serviços, mas que articule benefícios e serviços socioassistenciais com políticas sociais e econômicas,

Trata-se de um estudo teórico que tem como perspectiva analítica o Materialismo Histórico Dialético, realizado em documentos institucionais e normativos da seguridade social Brasileira. O universo de estudo abrangeu: o Anuário Estatístico da Previdência Social, 2011 a 2012; a Resolução no 1.241, de 30 de junho de 2004 do Conselho Nacional da Previdência; a Constituição Federal de 1988, - Capítulo da Seguridade Social artigos 194, 201 e 203 e a Lei Orgânica de Assistência Social.

Este estudo parte da concepção de seguridade social "entendida como padrão de proteção social de qualidade, com cobertura universalizada para situações de risco, vulnerabilidade ou danos dos cidadãos brasileiros" (CFESS/CRESS, 2000). A seguridade social pode proporcionar uma maior "liberdade" aos indivíduos que, diante das necessidades materiais e das contingências da vida, não lhes deixa escolha. Não nos referimos à concepção individualista de liberdade, mote do Estado de Burguês, mas no sentido de necessidade de reprodução social da força de trabalho de forma a participar da luta de classes (Marx e Engels, 1998). A seguridade social deve restringir o arco de insegurança do indivíduo e de sua família, colocando-os em condições de fazer frente a certas contingências sociais: velhice, doença e desocupação, pobreza.

Atualmente, o sistema capitalista apresenta-se renovado, com uma nova roupagem, como forma de reprodução das suas condições históricas de produção/reprodução, o que vem sendo denominado como neoliberalismo. Na contemporaneidade, as demandas sociais se aprofundaram. O capitalismo procura se reestruturar em função dessas novas demandas e de suas crises. Como resultado da reestruturação do capital vivenciam-se processos de flexibilização do trabalho, do mercado, do consumo e da produção de mercadorias (Harvey, 1992); financeirização do capital globalizado e mudanças na relação Estado e sociedade civil impostas pelo Consenso de Washington. 
Para Antunes (1995), o processo de reestruturação da reprodução do capital, com o trânsito da acumulação flexível, trouxe grandes consequências para o mundo do trabalho. Gerou a desproletarização do trabalho industrial, o crescimento do setor terciário conjugado à complexibilização do trabalho em duas direções. De um lado o trabalho intelectualizado e qualificado (que não deixa de ser estranhado) e, do outro lado, a desqualificação do trabalho com a subproletarização, a terceirização e o trabalho precário. As mudanças levaram a uma "desordem do trabalho" com insegurança no mercado de trabalho e na renda . Implicou, também, na desarticulação na representação do trabalho, na organização sindical e na defesa do trabalho.

Tais rebatimentos no mundo do trabalho recaem sob a seguridade social, especificamente na previdência social e na assistência social. São milhões de indivíduos excluídos do mercado formal, fora das relações de venda de trabalho - não segurados da previdência. Dessa forma ficam os seguintes questionamentos: Como ficam estes indivíduos não segurados da previdência social? Resta para eles uma "inseguridade social" ou lhes é garantido o direito uma segurança social?

Não cabe à política de assistência social dar conta da totalidade da questão social que recai sobre a força de trabalho. Mas uma seguridade social que não assegure segurança à força de trabalho perde o equilíbrio que deveria ser proporcionado pelo tripé da seguridade social (saúde, assistência, previdência) para ficar somente sobre "dois pés" (saúde e previdência).

Estudar o tema "seguridade social brasileira e proteção dos socialmente desprotegidos" tendo como objeto de estudo o "alcance do direito à previdência social e à assistência social aos socialmente desprotegidos" faz-se importante no atual contexto brasileiro. No campo da temática da assistência social, a discussão da proteção da força de trabalho não é pautada, quase que ausente. Por isso da relevância do estudo. Por essas razões, o objetivo deste artigo é refletir se a atual conformação da seguridade social brasileira permite levar à universalização da mesma.

O artigo está organizado da seguinte forma: primeiro segue uma introdução ao tema e objeto. Segundo, discute-se a articulação entre proteção e desproteção social da força de trabalho no capitalismo contemporâneo. Terceiro, o alcance do direito à previdência social e à assistência social aos desprotegidos socialmente. Ao final seguem as conclusões.

\section{A ARTICULAÇÃO ENTRE PROTEÇÃO E A DESPROTEÇÃO SOCIAL DA FORÇA DE TRABALHO NO CAPITALISMO}


Marx, em sua teoria, defendeu que na sociedade moderna a força de trabalho adquiriu a condição de mercadoria (coisa, valor de troca), pois "a procura de homens regula necessariamente a produção de homens como qualquer outra mercadoria" (MARX, 2006, p.66). Para ele, a força de trabalho tornou-se propriedade ou propriedade alheia com valor que existe por si mesmo como capital - trabalho acumulado - onde o trabalho vivo se apresenta "numa relação de não propriedade relativamente à matéria prima, aos instrumentos e meios de subsistência necessários durante o período de produção" (Marx, 1986, p. 93). Por meio da troca, o Capital se apropria, não do trabalhador, mas de seu trabalho. Se a oferta de força de trabalho é maior que a procura, a mercadoria força de trabalho é desvalorizada e parte dos trabalhadores cai na fome ou na miséria. Os "trabalhadores que precisam vender a si próprios, aos poucos são mercadoria como qualquer outro artigo de comércio e são, por consequência, expostos a todas as vicissitudes da competição, a todas as flutuações do mercado" (Marx; Engels, 1998, p. 20). Por isso "a existência do trabalho torna-se reduzida às mesmas condições de qualquer outra mercadoria" (Marx, 2006, p. 66).

O processo histórico de dissolução das relações de servidão, de propriedade, de corporativismos e de clientelas, antes existentes nas sociedades pré-capitalistas, sobrepôs o valor de uso da força de trabalho pelo valor de troca com pagamentos em dinheiro (Marx, 1986). Tal processo também transformou a massa de indivíduos "em potenciais trabalhadores - assalariados livres - indivíduos forçados, simplesmente por sua carência de propriedade, a trabalhar e a vender seu trabalho" (Marx, 2006, p. 99). Ele "separou a massa de indivíduos de suas anteriores relações afirmativas com as condições objetivas e de trabalho, que negou tais relações e, portanto, transformou tais indivíduos em trabalhadores livres" (Marx, 2006, p.99). Esse processo liberou as condições objetivas de trabalho de suas ligações prévias de trabalho (matérias primas, terra, instrumentos de trabalho e meios de subsistência, dinheiro ou ambos) separando os indivíduos das mesmas (Marx, 2006).

Como a força de trabalho não pode ser acumulada como qualquer outra mercadoria, o trabalhador é forçado a vendê-la diariamente para garantir a sua reprodução social. O custo da produção da força de trabalho torna-se tão restrito que chega ao ponto de prover somente a propagação e a manutenção dos trabalhadores. O trabalhador não é livre para vender sua força de trabalho, já o capitalista é livre para comprá-la ou não.

No capitalismo, a separação do trabalho de outras atividades da vida por meio do contrato individual de trabalho, sujeitou os indivíduos às leis do mercado. Isso "foi o mesmo que aniquilar todas as formas orgânicas da existência e substituí-las por um tipo diferente de 
organização, uma organização atomista e individualista" (Polanyi, 2000, p. 198) ${ }^{1}$. A transformação da terra e do trabalho em mercadorias fictícias enfraqueceu as instituições culturais das sociedades primitivas o que despojou, em parte, o indivíduo de suas organizações não contratuais de parentesco, vizinhança, profissão e credo, para o mercado. A "liberdade" de vender a força de trabalho passou a ser influenciada pela "escolha" de ficar sem alimento ou vender a sua força de trabalho no mercado ao preço oferecido pelo mercado. O contrato de trabalho individual liberou a força de trabalho para ser transformada de vez em mercadoria vis-à-vis do mercado (Polanyi, 2000).

$\mathrm{O}$ enfraquecimento de redes institucionais que garantiam a reprodução social do indivíduo fora do contrato social e a condição de mercadoria "força de trabalho" levou à mercadorização das pessoas (Esping-Andersen, 2001). O risco de ficar sem dinheiro na velhice, no desemprego ou na doença não era mais coberto pelos mecanismos tradicionais da solidariedade familiar, das ligações pessoais (Faleiros, 1997). A reprodução social do indivíduo, nessa lógica, ficou subordinada ao mercado.

Ocorre que existe uma contradição inescapável no capitalismo de livre mercado: a sujeição do indivíduo vis-à-vis às leis do mercado, se levada às últimas consequências, levaria à destruição da mesma. Sem as redes tradicionais de proteção - seja por organizações não contratuais de parentesco, vizinhança, profissão, credo ou pelo Estado - o indivíduo (força de trabalho e consumidor) não teria condições de se proteger das têmperas do mercado. "Despojados da cobertura protetora das instituições culturais, os seres humanos sucumbiriam sob os efeitos do abandono social [...]" (Polanyi, 2000, p. 95). Muito menos the daria condições de consumir as mercadorias produzidas pelo sistema capitalista, levando ao subconsumo e à crise do Capital. Por isso a proteção social da força de trabalho interessa tanto ao trabalho (classe que vive da venda sua força de trabalho) como ao Capital. Mas para atender ao Capital, essa proteção não deve impedir a formação de um exército de força de trabalho de reserva. Tal proteção deve ser residual, sujeita às leis do mercado.

Para Castel (2008, p. 41), historicamente, “As populações que dependem de intervenções sociais diferem, fundamentalmente, pelo fato de serem ou não capazes de trabalhar, e são tratadas de maneira completamente distinta em função de tal critério". Isso pode ser atribuído, também, a uma moral de que o indivíduo deve manter a si por meio do seu trabalho.

\footnotetext{
${ }^{1}$ O diálogo com os autores não marxistas com Castel (2008), Esping-Andersen (2001), Polanyi (2000) e Ricardo (1979) não retiram o caráter do referencial adotado. Consideramos que tais autores trazem estudos e reflexões que vêm contribuir para a apreensão da realidade.
} 
Para as forças antiprotecionistas do liberalismo econômico do século XVIII, (i) o homem deve manter a si e a sua família com os ganhos de seu trabalho e, (ii) se protegido, não trabalhará para obter salário. Para Polanyi (2000), tais princípios influenciam as políticas sociais até hoje.

Tal moral caminha lado a lado com o ideário liberal. Por tal ideal, os homens devem se colocar livres no mercado, cada qual com sua capacidade e esforço, "em pé de igualdade de oportunidades, segundo a capacidade de cada indivíduo" (Vieira, 2006, p. 70). Tal princípio liberal esteve presente no pensamento político, econômico e social da Revolução Francesa. liberdade, igualdade e fraternidade (sef-help ou auto-ajuda). Esse princípio se apresentava “como antítese do conceito de proteção social próprio da sociedade pré-industrial, calçado no paternalismo e no vínculo de dependência entre o pobre e o Estado" (Pereira, 2008, p. 33). Por essa concepção, a "assistência estimula o ócio, a preguiça e desestimula o trabalho, devendo ser abolida ou garantida apenas para os pobres e incapazes de manter sua sobrevivência pelo trabalho: crianças, idosos e deficientes" (Boschetti, 2001, p. 34).

Ocorre que é importante para avanço das forças produtivas a manutenção e a reprodução da força de trabalho e a produção de um exército de reserva. Pois "o trabalho, como todas as outras coisas que se compram e vendem e que podem ser aumentadas ou diminuídas, tem seu preço natural e o preço de mercado" (Ricardo, 1979, p. 299). Na concepção do liberalismo econômico "O mercado e suas leis fornecessem e regulam o valor das pessoas e das coisas" (Vieira, 1992, p. 70). Portanto, a oferta da mercadoria de força de trabalho no mercado e sua procura influem o seu preço, aumentando ou diminuindo o Capital.

Assim, tende a ser importante para o Capital que a força de trabalho não encontre proteção total no Estado de forma a ficar sujeita aos ditames do mercado.

\section{AS LÓGICAS DA SEGURIDADE SOCIAL BRASILEIRA}

A seguridade social não é sinônimo, nem se confunde com welfare state, Etat Providence ou Sozialstaat. A proteção social da seguridade social tem pelo menos três elementos - seguros, auxílios e assistência médica - e não se restringe ou se confunde com seguro social (BOSCHETTI, 2001).

Historicamente "o conceito de seguridade social traz em si uma noção heurística de "seguro social" [...] que, para se efetivar, deve assegurar direitos que não se restrinjam à lógica do seguro social contributivo" (Boschetti, 2001, p. 36, tradução nossa). Dessa forma, os países trazem consigo os princípios contributivos e não contributivos para a concepção de 
seus sistemas de seguridade social, que se impõem com menor ou maior predominância segundo suas formações econômicas, sociais e culturais (Boschetti, 2001). A relação histórica entre esses dois princípios que são inerentes à seguridade social "faz com que, contraditoriamente, estas políticas vivam uma relação de atração e rejeição, construindo assim uma unidade de contraditórios" ( BOSCHETTI, 2001. P. 36).

Boschetti (2001) argumenta que o "princípio moral de que assistência estimula o ócio, a preguiça e desestimula o trabalho, devendo ser abolida, ou garantida apenas para os pobres e incapazes de manter sua sobrevivência pelo trabalho: crianças, idosos e deficientes" (Boschetti, 2001, p. 34) orientou a concepção das políticas sociais no final do século XIX e que foram consolidadas pós-guerra conformando e consolidando o estado social ${ }^{2}$. Para a autora ocorreu a incorporação desse princípio na seguridade social brasileira, sobretudo nos benefícios e serviços da previdência e assistência social.

A seguridade social no Brasil sustentou-se em dois modelos de políticas sociais. Um foi o modelo bismarkiano que fundou o sistema previdenciário alemão entre 1883 e 1888 orientado por uma Lógica Contributiva da Seguridade Social e que visou assegurar renda aos trabalhadores nos momentos de risco sociais decorrentes da ausência de trabalho. Ele é identificado como "sistema de seguro social" por sua semelhança aos seguros privados, uma vez que os benefícios dependem da contribuição direta anterior, sendo proporcional à contribuição efetuada. Sua base de financiamento são recursos recolhidos de empregadores e empregados com predominância na folha de salários (BOSCHETTI e SALVADOR, 2006).

Trata-se de um tipo limitado de proteção social, uma vez que garante direitos somente àquele que contribui mensalmente para a seguridade social e está inserido no mercado de trabalho formal e por vezes informal. Sob esta lógica, só tem acesso aos direitos (saláriomaternidade, auxílio doença, pensões, assistência médica) os "segurados" e seus dependentes. Essa lógica impõe um limite estrutural para seguridade social, pois depende da constituição de um mercado de trabalho. "Este modelo só universaliza direitos sociais se universalizar, igualmente, o direito ao trabalho" (Boschetti, 2008, p. 177). Isso porque ele está condicionado ao acesso do trabalhador a um mercado de trabalho estável que gere contribuição ${ }^{3}$. A previdência social regida pela lógica do seguro foi a forma que o capitalismo encontrou para

\footnotetext{
${ }^{2}$ Boschetti (2001) ao utilizar o conceito estado social, refere-se genericamente à ação do estado capitalista na regulação das políticas sociais em contextos históricos e socioeconômicos específicos: Welfare States, Estado Providência e Estado de Bem-Estar.

${ }^{3}$ Para Boschetti (2008), quando se afirma a universalização ou a quase universalização da seguridade social nos países nórdicos da Europa, trata-se de um período histórico determinado - entre 1940 a 1970 - quando aquelas sociedades, ao quase alcançaram o pleno emprego, garantiam seguridade social a quase todos os trabalhadores.
} 
garantir um mínimo social para os trabalhadores que só dispõem de sua força de trabalho para viver ("não proprietários").

Este modelo parte de uma cidadania (no caso a seguridade social) condicionada ao trabalho e à contribuição. Somente tem direito aqueles que participaram das relações mercantis de trabalho e que contribuíram previamente para a sua proteção social. A partir dessa lógica, a proteção social do indivíduo está primeiro no mercado, onde deve participar das relações mercantis de exploração ou de venda de força de trabalho e contribuir (pagar) a sua proteção social de seguridade social.

O segundo modelo - beveridgiano ${ }^{4}$ - surgiu durante a Segunda Guerra Mundial na Inglaterra. Ele foi fundado a partir uma Lógica não Contributiva da Seguridade Social e tinha como objetivo principal o combate à pobreza. Tratava-se de direitos universais dirigidos a todos os cidadãos independentes de contribuições, baseado na uniformização dos benefícios e unificação institucional (Boschetti, 2006). Esse sistema é oposto ao modelo bismarkino, pois não propõe uma seguridade social limitada a um seguro social que funcionasse aos moldes de um plano privado.

Tal modelo, ao contrário do outro, não parte de uma cidadania (no caso a seguridade social) condicionada no trabalho e na contribuição. Nele, todos têm direito à seguridade social independente da participação dos indivíduos nas relações mercantis de trabalho ou de contribuição ${ }^{5}$.

No Brasil, a Constituição Federal de 1988 estabeleceu a Seguridade Social como um conjunto integrado de ações do Estado e da sociedade destinado à saúde, à previdência e à assistência social. O tripé da seguridade social brasileira - Saúde, Assistência Social e Previdência - é formado a partir de dois pressupostos: (i) a Lógica Contributiva da Seguridade Social que orienta os princípios da Previdência Social e (ii) a Lógica não Contributiva da Seguridade Social que orienta os princípios da Saúde e da Assistência Social. Assim, os direitos previstos pela Seguridade Social foram "inscritos em situações distintas, ficando a previdência social dependente de contribuição, a assistência da necessidade e

\footnotetext{
${ }^{4}$ Os princípios do welfare state, segundo o Plano Beveridge publicado em 1942 na Inglaterra eram: a) universalização dos serviços sociais; b) responsabilidade estatal na manutenção das condições de vida dos cidadãos, com um conjunto de ações em três direções: regulação da economia de mercado para manter um elevado nível de emprego; prestação pública de serviços sociais universais (educação, assistência médica, segurança social e habitação e um conjunto de serviços sociais pessoais; e c) implantação de um sistema de segurança de serviços de assistência (Boschetti, 2001).

${ }^{5}$ Entretanto, é importante ressaltar, mesmo que este modelo proponha a universalização da proteção social, sem base na contribuição, não deixa de ser uma política social capitalista, que pode atender tanto aos interesses do capital e do trabalho (classe que vide da venda da sua força de trabalho).
} 
somente a saúde tendo se universalizado de fato, sem nenhum critério prévio de acesso" (LOBATO, 2006, p. 2).

A especificidade do direito constitucional de assistência social brasileiro é a medida (peso) em que tal direto é regido pela Lógica Contributiva da Seguridade Social e pela Lógica não Contributiva da Seguridade Social. Se regido pela Lógica Contributiva da Seguridade Social, a proteção social do indivíduo estará (i) no mercado participando das relações mercantis de trabalho para comprar produtos e serviços, ou quando da ausência de tais meios, estará (ii) nas formas tradicionais de proteção social (caridade, tutela, família). Se regida pela Lógica não Contributiva da Seguridade Social, independente do trabalho ou da contribuição prévia, o indivíduo terá a sua proteção social assegurada pela sociedade, por meio do Estado. O peso de cada uma dessas lógicas irá determinar a universalização ou seletividade do direito. Se regido ao mesmo tempo por estas duas lógicas, a proteção do indivíduo estará primeiro no mercado, participando das relações mercantis de trabalho, para obter a proteção comprando serviços e produtos e segundo estará nas formas tradicionais e proteção (família) e, na ausência de tais meios, estará na sociedade por meio do Estado. Ou seja, se regido por estas lógicas contraditórias, a proteção de assistência social do indivíduo deverá estar primeiro no mercado, segundo na família, e terceiro - de forma subsidiária, no Estado.

\section{O ALCANCE DO DIREITO À PREVIDÊNCIA SOCIAL E À ASSISTÊNCIA SOCIAL AOS SOCIALMENTE DESPROTEGIDOS}

Em 2004, o Conselho Nacional da Previdência Social (CNPS) aprovou em plenária a Resolução $\mathrm{n}^{\mathrm{o}}$ 1.241/2004 que estabeleceu uma metodologia de cálculo da cobertura previdenciária, adotando-se os conceitos de população socialmente protegida e socialmente desprotegida. Tais conceitos são relevantes porque, primeiro, permitem delimitar, mensurar a população socialmente protegida e desprotegida da seguridade social; assim eles proporcionam uma direção para estudos, pesquisas e análises da implementação de políticas sociais. Segundo, esses conceitos apontam, em suas entrelinhas, uma concepção de proteção social no âmbito seguridade social adotada pelo Estado brasileiro. Isso permite delimitar e conceituar sob qual prisma o Estado brasileiro compreende por proteção de seguridade social. Eles também proporcionam análises empíricas em relação à efetivação dessa dada proteção; sobretudo, se está sendo efetivada ou não. 
Conforme a Resolução $n^{\circ} 1.241 / 2004$ do CNPS, a população socialmente protegida é aquela que tem a cobertura da previdência social ou da assistência social e socialmente desprotegida é aquela que não possui nenhuma destas coberturas ${ }^{6}$.

[...] não contribuem para a Previdência Social, não recebem nenhum benefício e não se enquadram na categoria de segurados especiais (trabalhadores rurais que contam com proteção previdenciária mesmo com contrapartida contributiva diferenciada) (CNPS, 2004).

Para fins de proteção social, o Ministério da Previdência Social (MPS) considera o recebimento da Renda Mensal Vitalícia (RMV) e do Benefício de Prestação Continuada (BPC) como indicadores de cobertura da assistência social. Quem não tem cobertura da previdência social e, ao mesmo tempo, não é usuário do BPC ou da RMV está inserido na categoria dos socialmente desprotegidos.

Ocorre que o RMV e o BPC são destinados somente às pessoas idosas e com deficiência que se inserem nos critérios de habilitação. Esses critérios conjugam idade, incapacidade para o trabalho e extrema pobreza. Os indivíduos com idade inferior a 65 ou os que não têm deficiência que os incapacite para o trabalho e a vida independente, não tem acesso a eles.

Tais conceitos nos permitem visualizar e apreender a concepção de proteção social que o Estado brasileiro adota no âmbito da seguridade social. A análise em curso nos permitiu deduzir que, se todos os protegidos da seguridade social são aqueles considerados os segurados da previdência e os beneficiários da RMV e do BPC, os não segurados e os não usuários do RMV e do BPC estão socialmente desprotegidos. Assim, ser usuário dos serviços socioassistenciais das políticas de Proteção Social Básica e Especial da Assistência Social não significa estar socialmente protegido.

O resultado disso é que o Estado brasileiro concebe proteção social no âmbito da seguridade social primeiro, como garantia de renda. Segundo como uma pecúnia que possibilite a reprodução social do indivíduo. Também está implícito nos referidos conceitos um parâmetro de um mínimo social não inferior ao salário mínimo da legislação social brasileira. Terceiro, que essa pecúnia não deve ser eventual. Finalmente, que a proteção social da seguridade social não deve se limitar à prestação serviços sociais e socioassistenciais. Ela

\footnotetext{
${ }^{6}$ Tratam-se de conceitos utilizados pelo Ministério da Previdência Social (MPS) e pelo Instituto Brasileiro de Geografia e Estatística (IBGE) em suas análises quantitativas sobre alcance da proteção social da seguridade social no Brasil.
} 
deve garantir a satisfação das necessidades imediatas dos indivíduos de forma a manter a sua reprodução social. A intenção das autoras do presente artigo não é defender tal concepção, mas apreender, nas entrelinhas, a concepção de proteção social implícita em tais conceitos e adotada pelo MPS.

Tal concepção se encontrava obscura e diluída no arcabouço normativo da seguridade social. A análise mais profunda dela, sobretudo da Resolução $n^{\circ}$ 1.241/2004 do CNPS, possibilitou aprofundar e descortinar esse entendimento. Esse caminho proporcionou desvendar e trazer à tona algumas contradições da proteção social no âmbito da seguridade. A partir daí formulou-se a seguinte questão: A atual conformação da seguridade social permite que ele venha a se universalizar? Para este estudo não.

Um estudo da Previdência Social, com base na Pesquisa Nacional por Amostra de Domicílios (PNAD) demonstra que, entre 2009 e 2011 o número de trabalhadores cobertos pelo sistema previdenciário saltou de 56,58 milhões para 60,47 milhões (MPS, 2012a). Em 2011, esta proteção previdenciária representava 70,7\% da população ocupada em todo o país (85,55 milhões), contra 67\% em 2009.

Figura 1: BRASIL - Panorama da Proteção Social da População Ocupada (entre 16 e 59 anos) 2011 - (Inclusive a Área Rural da Região Norte).

Figure 1: BRAZIL - Overview of Social Protection of the employed population ( between 16 and 59 years) - 2011 - (Including Rural Area of the Northern Region )

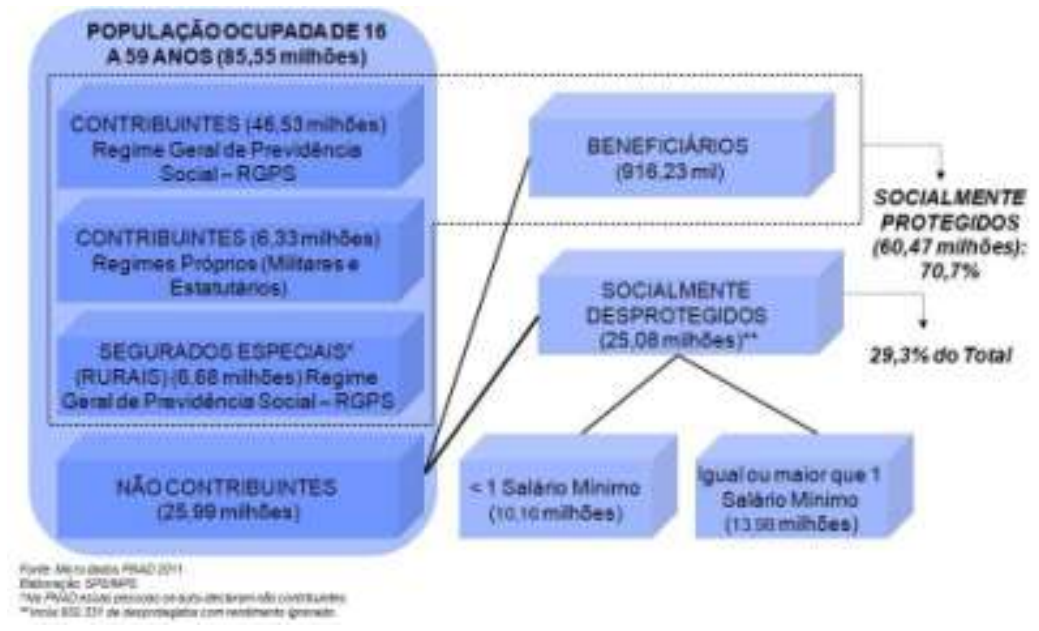

.Fonte: MPS. Evolução da Proteção Social e Impactos sobre a Pobreza - 1992 a 2011. Brasília, outubro de 2012.

Entre os 70,7\% (60,47 milhões de pessoas) socialmente protegidos, estão 46,53 milhões de contribuintes do Regime Geral de Previdência Social (RGPS), 6,68 milhões de trabalhadores rurais - os segurados especiais - e os servidores públicos vinculados aos 
regimes próprios de previdência social - 6,33 milhões de pessoas. Também estão socialmente protegidas 910 mil pessoas que não contribuíram para a previdência, mas recebem algum tipo de auxílio (MPS, 2012b).

Apesar do crescimento da proteção previdenciária, 25,08 milhões de brasileiros ainda estão socialmente desprotegidos. Isso corresponde a $29,3 \%$ do total da população ocupada (MPS, 2012b). Cerca de metade dos desprotegidos em 2011 (13,9 milhões) possuem capacidade contributiva e está na faixa dos 30 a 39 anos (4 milhões), ganham entre um e dois salários mínimos (7,2 milhões) e reside na região sudeste (6,1 milhões) (MPS, 2012a) ${ }^{7}$.

Ainda, dentro da categoria dos desprotegidos, cerca de $40 \%$ (10,16 milhões) possuíam rendimento inferior ao valor do salário mínimo e, portanto, dificilmente teriam condições de contribuir para a Previdência. Além de possuírem taxa de proteção social mais baixa, as mulheres são maioria entre os desprotegidos sem capacidade contributiva e minoria entre os desprotegidos com capacidade contributiva (MPS, 2012b).

A renda transferida pela Previdência Social é utilizada para substituir a renda do trabalhador contribuinte, quando ele perde a capacidade de trabalho, seja pela doença, invalidez, idade avançada, morte e desemprego involuntário ou mesmo a maternidade e a reclusão (MPS, 2012b). Os dados do MPS (2012b) demonstram a situação de vulnerabilidade e risco social de grande parte da população brasileira, questão social que não deve ser desconsiderada.

No Brasil, a questão social é conexa à inserção do país na nova ordem mundial capitalista em uma relação subalterna em relação aos países centrais. Em tal contexto, os processos de acumulação e reestruturação do capital têm aprofundado a questão social (Iamamoto, 2001) resultando em desigualdades sociais, políticas, econômicas e culturais entre as classes sociais. Essas disparidades são mediadas por relações étnico-raciais, de gênero e por formações geracionais. Assim, a pobreza vai além da distribuição de renda. Refere-se à distribuição dos meios de produção que atingem a totalidade da vida humana: cultural, necessidades vitais, morais e intelectuais.

Conforme o Capital cresce, aumenta também o "exército de reserva" do mercado - os "supérfluos" e "inúteis" para o capital e o mundo: os sem-terra, os sem-teto, os trabalhadores temporários e em situação de trabalho precário, os desempregados e os não empregáveis (Iamamoto, 2001).

\footnotetext{
${ }^{7}$ A população que detém capacidade contributiva é que trabalha e tem renda suficiente para ser contribuinte da Previdência Social.
} 
Nesse contexto de exclusão, encontra-se a força de trabalho; aquela em vias de participar das relações de trabalho que são os maiores de 16 anos, potenciais contribuintes da Previdência Social. Entretanto, não contribuem por não conseguirem ingressar no mercado de trabalho ou por trabalharem em situação precária, sem renda suficiente para "pagar" sua previdência social pública.

Diante das metamorfoses no mundo do trabalho (Antunes, 1995), muitos indivíduos nem mesmo chegam a adquirir o status da mercadoria força de trabalho. A pobreza relativa que afeta a totalidade de suas vidas torna-os não empregáveis e invisíveis para o mercado. Portanto, nunca serão segurados da Previdência Social.

Assim a sociedade tem as seguintes questões: Proteger ou não estes indivíduos e como? Se eles não são protegidos pela previdência social, a quem caberá?

Outro objetivo no debate se refere à análise do alcance do direito à previdência social e da assistência social aos socialmente desprotegidos.

Vale dizer que a seguridade social que se inscreve na Constituição Federal de 1988, no artigo 194, que diz: "O conjunto integrado de ações de iniciativa dos Poderes Públicos e da sociedade destinadas a assegurar os direitos relativos à Saúde, à Previdência e à Assistência Social".

No entanto, a seguridade social brasileira prevê, ao mesmo tempo, um alcance universal para a saúde; estratificado para a previdência, pois é condicionado a uma contribuição prévia; e seletivo para a assistência social, que é para quem dela necessitar. A política de assistência social se operacionaliza apenas por meio da prestação serviços socioassistenciais e por meio da concessão de benefícios destinados aos idosos e aos portadores de deficiência (RMV e do BPC). Ela não prevê um conjunto básico de garantia de reprodução social para os indivíduos socialmente desprotegidos.

A seguridade social não protege os indivíduos que estão em idade produtiva $^{8}$ e que não contribuem, seja por falta de trabalho ou por falta de renda que permita a contribuição. Ela também não protege aqueles que, apesar de terem renda suficiente, não contribuem por algum motivo.

Para as autoras, Behring e Boschetti (2011) a seguridade social no Brasil foi pensada a partir do pleno emprego, o que torna impossível a sua universalização. Primeiro, pelo próprio padrão desenvolvimento do trabalho no Brasil. Segundo, porque ela vem sofrendo os impactos já assinalados em função do desenvolvimento do capitalismo e suas refrações,

\footnotetext{
${ }^{8}$ Trata-se da população de 16 e 59 anos conforme a definição metodológica do MPS.
} 
interferindo nos direitos ao trabalho e no padrão de proteção social. Terceiro, a construção da proteção social brasileira se deu com a visível falta de sincronia com os processos internacionais.

Enquanto desencadeava-se uma reação burguesa, com o desmantelamento da proteção social, no Brasil, estávamos mergulhados no contexto da ditadura militar pós 1964 na qual se vivenciava a expansão do chamado "milagre brasileiro".

[...] padrão proposto para a construção de proteção social, de natureza pública, com direitos a educação, a saúde, ao trabalho, a moradia, o lazer, a segurança, a previdência social, a proteção à maternidade e à infância e assistência social, significou um dos mais importantes avanços na política social brasileira, com possibilidade de estruturação tardia de um sistema amplo de proteção social, mas não se materializou (Behring e Boschetti, 2011, p. 156).

Concordamos com a autora e mais, acrescentamos que a própria legislação e a conformação da seguridade social, nela incluída a assistência social, não incluiu a proteção dos socialmente desprotegidos. Isso torna impossível a universalização desse direito no âmbito legal e operacional. Não se trata apenas de fundo público, trata-se também de ampliação do direito com ampliação do leque de garantias de proteção a todos.

\section{CONCLUSÃO}

Ao longo da trajetória da política social, a proteção social dos indivíduos foi atribuída ora à sociedade - nela a família - ora ao mercado, ora ao Estado, ou a ambos. Seus destinatários variavam em função de deterem ou não de força de trabalho para manter a reprodução social.

Tais formas de proteção social como produto de uma relação dialeticamente contraditória refletem a correlação de forças de um dado lugar e tempo histórico. Elas levam a diferentes formas de proteção social, que se distanciam ou se aproximam entre si, porém nunca são iguais. Tempo, lugar, duração, objetivos, forma, destinação e ideologias nelas contidas fizeram de cada uma dessas proteções e políticas únicas. O que há de comum entre elas é que os segmentos populacionais que dependem de intervenções sociais diferem pelo fato de serem ou não capazes de trabalhar e são tratados de formas distintas em função disso. A diferenciação entre força de trabalho e não força de trabalho também se mantém na política social capitalista, desta vez com o atributo de mercadoria e de não mercadoria força de trabalho. Ela pode até proteger a mercadoria força de trabalho em caráter subsidiário, mas nunca de forma universalizada. 
Tal concepção, presente no ideário liberal, mesmo que não explícita, ainda "assombra" as formas de proteções sociais contemporâneas. Isso porque a política social capitalista, em sua essência, classifica os indivíduos entre aptos e inaptos, capazes e incapazes para o trabalho, aceitando assistência aos incapacitados e inaptos e tolerando uma proteção parcial e residual à força de trabalho.

Tal entendimento orientou a concepção das políticas sociais no final do século XIX que foram consolidadas no pós-guerra, conformando e consolidando o Estado Social (modelos liberal-residual e bismarkiano). Por isso a Política Social Capitalista na contemporaneidade articula a desproteção social da força de trabalho e a proteção da não força de trabalho. Para os que detêm dela para manter a sua reprodução social, o mercado será o lócus de "proteção". Tal proteção se dará com os indivíduos participando das relações de produção, consumindo produtos e serviços, entre eles a previdência privada ou pública. Quanto à proteção do Estado, aceitar-se-á a proteção social somente aos membros mais vulnerabilizados da sociedade, focalizando o direito naqueles que não são considerados mercadoria força de trabalho.

A seguridade social brasileira, prevista na Constituição Brasileira de 1988, é um exemplo típico de política social contemporânea que classifica, em sua essência, os não isentos e os isentos da obrigação do trabalho e destina a eles formas distintas e contraditórias de proteção social (previdência social contributiva para a força de trabalho e assistência social não contributiva para a não força de trabalho, os isentos socialmente da obrigação de trabalho).

O estudo analítico, consolidado nesse artigo, teve com aporte os conceitos de socialmente protegido e desprotegido adotados pelo Conselho Nacional da Previdência Social (CNPS), Resolução 1.241/2004. Nele, refletiu-se sobre o alcance da seguridade social aos socialmente desprotegidos. A partir de tais conceitos e da análise conformação do direito à previdência social e à assistência social, discutiu-se suas possibilidades de limites para a extensão da proteção da seguridade social àqueles que se encontram desprotegidos socialmente, conforme indicadores do MPS.

A compreensão desses conceitos levou a um entendimento de proteção social, no qual existe uma relação de complementaridade entre o direito à previdência social e à assistência social, sem possibilidade de universalização desta proteção. $\mathrm{O}$ direito de acesso à seguridade social está restrito aos que são segurados da previdência social ou aqueles que estão no RMV 
e no BPC (população não economicamente ativa). A população que não se inscreve nessas políticas não tem a proteção do Estado, independente da renda.

A universalização da seguridade social no Brasil requer não só a indissociabilidade e complementaridade entre as duas políticas - de previdência e de assistência social - como também políticas econômicas e sociais onde o trabalho e a garantia de reprodução social dos indivíduos sejam tidos como direitos de cidadania. Isso requer mudanças estruturais na distribuição e redistribuição da riqueza socialmente produzida.

A legislação e a conformação da seguridade social, nela a da assistência social, não incluiu a proteção dos socialmente desprotegidos, o que torna impossível a universalização desse direito.

\section{REFERÊNCIAS}

ANTUNES, R. Adeus ao Trabalho? 2a ed., São Paulo, Cortez, 2000.

BOSCHETTI, I. Assistência Social no Brasil: um direito entre originalidade $e$ conservadorismo. $1^{\text {a }}$ ed., Brasília. Universidade Nacional de Brasília/UNB / Grupo de Estudos de Seguridade Social e Trabalho, 2001. p, 182.

BOSCHETTI, I. et al (org.). Política Social no Capitalismo: tendências contemporâneas. São Paulo: Cortez, 2008.

BOSCHETTI, I. ; SALVADOR, E. Orçamento da seguridade social e política econômica: perversa alquimia. In: Serviço Social e Sociedade. Ano XXVII, n. 87. São Paulo: Cortez, 2006.

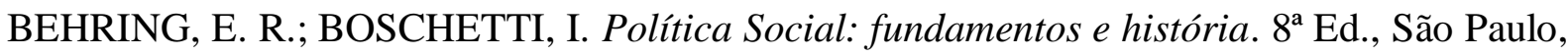
Cortez 2011(Biblioteca básica de serviço social; v. 2).

CASTEL, R. As metamorfoses da questão social: uma crônica ao salário. Tradução Iraci D. Poleti. 7. ed. - Petrópolis. RJ: Vozes, 2008.

CFESS/CRESS. 2000. Carta de Maceió Seguridade Social Pública: é possível! In: XXIX Encontro Nacional CFESS/CRESS, Maceió (AL), 3 a 6 de set. de 2000.

ESPING-ANDERSEN, Costa. Fundamentos Sociales de Las Economias Postindustri. Ariel Publications. 2001.

FALEIROS, V. P. A Política Social do Estado Capitalista. As Funções da Previdência e da Assistência Social. São Paulo, Cortez, 1997.

IAMAMOTO, M. V. A Questão Social no Capitalismo. In: Temporalis / Revista da Associação Brasileira de Ensino e Pesquisa em Serviço Social - ABEPSS, Ano 2, n. 3 (jan/jun.2001). Brasília, ABEPSS, 2001.

LOBATO, L. de V. C. Valor Público, Capital Institucional e a Construção de Direitos Sociais: a experiência de um benefício assistencial brasileiro. In: XI Congresso Internacional de

CLAD sobre la Reforma el Estado y de Administración Pública, Ciudad de Guatemala, 7 - 10 nov. 2006. Disponível em: <

http://www.portal.cnd.gob.pe/archivos/clad/cocumentos/lobato.pdf> Acesso em 20 de jan. de 2012.

MARX, K; ENGELS, F. O Manifesto Comunista. Rio de Janeiro: Paz na Terra, 1998. MARX, K. Manuscritos Econômicos-filosóficos. Trad. MARTINS, Alex. Coleção a Obra Prima de Cada Autor. Editora Marin Claret. São Paulo, 2006. 
POLANY, K. A Grande Transformação: as origens da nossa época. Tradução Fanny Wrobel. - 2 ed. - Rio de Janeiro: Campos, 2000.

PEREIRA, P. A. P. Política Social Temas \& Questões. São Paulo: Cortez, 2008.

RICARDO, D. Princípios da Economia Política. São Paulo: Abril Cultural, 1979. (Os

Pensadores).

VIEIRA, E. Os direitos e a política social. São Paulo: Cortez, 2004.

\section{LEGISLAÇÃO E DOCUMENTOS}

BRASIL. Constituição da República Federativa do Brasil, promulgada em 05 de out. de 1988. Brasília, 1988.

CNPS. Resolução $n^{o} 1.241$, de 30 de jun. de 2004. Aprova a metodologia de cálculo da cobertura previdenciária, adotando-se os conceitos de população socialmente protegida e socialmente desprotegida. Brasília, 2004.

MPS. PNAD 2011: Cresce proteção social e previdenciária da População Ocupada. Disponível em: <http://www.MPS.gov.br/vejaNoticia.php?id=48044\#>. Acesso em 30, out. 2012a.

MPS. Proteção Previdenciária - Perfil dos socialmente desprotegidos segundo a Pesquisa Nacional por Amostra de Domicílios - PNAD 2009. Disponível em: < http://www.MPS.gov.br/arquivos/office/3_110531-145025-511.pdf >. Acesso em 30, out. $2012 b$.

\section{Raquel Sabará Freitas}

Assistente Social. Mestre em Serviço Social. Professora do Magistério Superior.Universidade Federal do Tocantins (UFT).

E-mail: raquelsabara@mail.uft.edu.br

Endereço: Universidade Federal do Tocantins, Campus de Miracema. Av. Lourdes Solino, s/n Setor Universitario - CEP: 77650000 - Miracema do Tocantins, TO - Brasil

\section{Maria Helena Cariaga}

Bacharel em Serviço Social pela Pontifícia Universidade Católica de São Paulo (1983). Mestre em Serviço Social pela Pontifícia Universidade Católica de São Paulo (2005). Doutora também pela Pontifícia Universidade Católica de São Paulo. Experiência profissional na coordenação de programas, projetos e pesquisas sociais. Com enfase na implementação, execução e avaliação de políticas publicas, na área da politica de assistência social, politica de saúde e demais politicas destinadas as famílias em situação de vulnerabilidade social . Pesquisadora e Professora Adjunto I (2008) da Universidade Federal do Tocantins - UFT.

E-mail: mhcariaga@gmail.com

Endereço: Universidade Federal do Tocantins, Campus de Miracema. Av. Lourdes Solino, s/n Setor Universitario - CEP: 77650000 - Miracema do Tocantins, TO - Brasil 